NBER WORKING PAPER SERIES

\title{
YOUNG WORKERS, OLD WORKERS, AND CONVERGENCE
}

\author{
Michael Kremer \\ Jim Thomson
}

Working Paper No. 4827

\author{
NATIONAL BUREAU OF ECONOMIC RESEARCH \\ 1050 Massachusetts Avenue \\ Cambridge, MA 02138 \\ August 1994
}

We thank Robert Barro, Jess Benhabib, Olivier Blanchard, Greg Mankiw, Kiminori Matsuyama, and Nancy Stokey for helpful comments. This paper is part of NBER's research program in Growth. Any opinions expressed are those of the authors and not those of the National Bureau of Economic Research.

(C) 1994 by Michael Kremer and Jim Thomson. All rights reserved. Short sections of text, not to exceed two paragraphs, may be quoted without explicit permission provided that full credit, including (C) notice, is given to the source. 


\title{
YOUNG WORKERS, OLD WORKERS, AND CONVERGENCE
}

\begin{abstract}
The human capital of young and old workers are imperfect substitutes both in production and in on-the-job training. This helps explain why capital does not flow from rich to poor countries, causing instantaneous convergence of per capita output. If each generation chooses its human capital optimally given that of the previous and succeeding generations, human capital follows a unique rational-expectations path. For moderate substitutability, human capital within each sector oscillates relative to that in other sectors, but aggregate human capital converges to the steady state monotonically, at rates consistent with those observed empirically.
\end{abstract}

Michael Kremer

Deparment of Economics

M.I.T.

E52-251C

Cambridge, MA 02139

and NBER

\author{
Jim Thomson \\ Department of Economics \\ University of Melboume \\ Parkville 3052 \\ AUSTRALIA
}


1. Introduction

In this paper, we examine how the optimal level of human capital for each generation depends on the human capital of the previous and succeeding generations. For a moderate degree of substitutability between the human capital of young and old, human capital within each sector of the economy oscillates relative to that in other sectors. Aggregate human capital, however, converges monotonically to the steady state, at rates consistent with those observed empirically by Barro and sala-iMartin [1992a] and Dowrick and Nguyen [1989]. Imperfect substitutability between the human capital of young and old workers can thus help explain why per capita output does not converge instantaneously, as predicted by the open-economy, neoclassical growth model.

The human capital of young and old workers are likely to be imperfect substitutes in production because young and old workers have comparative advantages in different, complementary tasks. Thus young workers are computer programmers, production line workers, and football players, whereas old workers are managers, foremen, and football coaches. In general, managers are likely to be older due to a need for experience, the ability to command respect from younger workers, and gradual learning about manager quality. The human capital of young and old workers are also likely to be imperfect substitutes in training new workers. 
Formal education may prepare people to learn the specific skills required in production that are actually taught through on-thejob training by older workers. Hence people with more formal education also receive more on-the-job training. Lawyers and doctors, for example, generally obtain extensive formal education and on-the-job training, whereas gas-station attendants usually obtain little of either.

Empirical evidence supports the view that the human capital of young and old workers are imperfect substitutes. At the macro level, Murphy and welch [1992] find that an increase in the number of young college-educated workers in the U.S. has either a small negative or a positive effect on the wage of old collegeeducated workers. At the micro-level, Pierce [1990] finds that an increase in the number of young lawyers has a positive (although not statistically significant) effect on the wages of old lawyers. While these estimates must be treated with caution given the short length of available time-series and the possible presence of other confounding factors, the differing movements of returns to young and old human capital provides evidence that they cannot be perfect substitutes. From 1979 to 1987 , for example, the wage differential between U.S. high school and college graduates increased by 31 percent among young workers, but by only 5 percent among old workers [Katz and Murphy, 1992].1

1 An alternative explanation of the small movements in

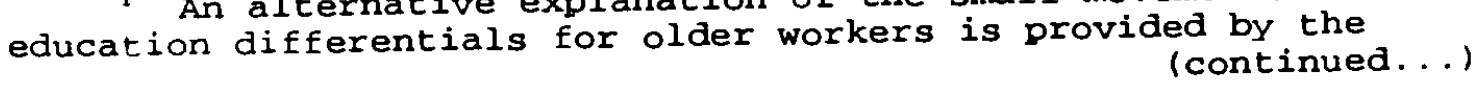


Similarly, Goldin and Margo [1992] find that the increase in the supply of young educated workers in the 1940's reduced their relative wage much more than that of old educated workers.

We take this imperfect substitutability between young and old human as given and explore how it affects the dynamic path of human capital. Since each generation's optimal level of human capital depends on that of the previous and succeeding generations, the rational-expectations path of human capital satisfies a second-order difference equation. Assuming there are decreasing returns to accumulable factors, this path will be unique and will converge to a steady state. We argue that for a moderate degree of complementarity between young and old human capital, the path of aggregate human capital will converge monotonically to the steady state, but that human capital in each sector of the economy will oscillate relative to that in other sectors.

This contrast arises because increases in old human capital within an individual sector will tend to reduce the price of that sector's output and thus reduce the return to young human capital in that sector. For example, if there are more old doctors, total output of medical services will increase, and this will drive down the price of medical services, causing the wage

1 (...continued)

"active labor market" hypothesis of Freeman [1975], in which older workers are insulated from labor market changes by unions, seniority rules, and firm-specific human capital.

Convergence 
for competing young doctors to fall. Thus, within an individual sector, the optimal amount of human capital for any generation is likely to fall with the human capital of the previous and succeeding generations. As Pierce [1990] has pointed out, this will tend to generate cycles in the level of human capital within particular sectors. (Freeman [1975a, 1975b, 1976] argues that the behavior of human capital in law, physics, and engineering is consistent with cycles, though he interprets this in terms of a cobweb model, rather than in terms of a rational-expectations model.)

This effect does not arise at the level of the aggregate economy, however, since an increase in old human capital spread across sectors, rather than concentrated in a particular sector, will not reduce the relative price of any good. If young and old human capital are complements in production, higher aggregate human capital of the previous and succeeding generations will increase the incentive for the current generation to accumulate human capital. The better the professors in the last generation, the greater the incentive to become a research assistant, and the better the next generation of research assistants, the greater the incentive to become a professor. We show that this complementarity implies that aggregate human capital will converge to the steady state monotonically.

The model can thus help explain why per capita output does not converge immediately, as predicted by the standard open- 
economy, neoclassical model. Under the standard neoclassical model, capital would flow instantaneously from rich countries, where its marginal product is low, to poor countries, where its marginal product is high. Under imperfect substitutability, however, convergence is not immediate because it is not optimal to invest too heavily in young human capital or physical capital given a fixed supply of old human capital. Thus, for example, Kenya would not wish to suddenly train thousands of chemical engineers because fresh-minted chemical engineers would have low productivity without supervision from more experienced engineermanagers. Imperfect substitutability can be interpreted as slowing convergence by creating a form of adjustment cost in human capital, since under imperfect substitutability total output depends positively on each generation's human capital, but negatively on the change in human capital between generations. As Alwyn Young has suggested in comments on Barro, Mankiw, and Sala-i-Martin [1992a], adjustment costs in human capital may help explain slow convergence.

This approach to explaining slow convergence can be contrasted with that of Cohen and Sachs [1986] and Barro, Mankiw, and Sala-i-Martin [1992], who explain the failure of per capita output to converge instantaneously through capital-market imperfections that make countries behave like closed economies. In their models, some share of investment has to be financed from domestic saving, so consumption smoothing causes gradual 
convergence to the steady state, just as in the closed-economy, neoclassical model. Capital market imperfections certainly exist and slow convergence. However, they do not seem sufficient to explain the huge income differences between rich and poor countries. Under the neoclassical model these differences would imply large differences in the marginal product of capital, and it is not clear why mechanisms would not develop to allow greater capital flows. In 1913, 488 of Argentina's capital stock and 208 of Australia's capital stock were foreign owned [Taylor, 1992], suggesting that capital-market institutions capable of handling large flows can arise given sufficient incentives. In contrast, Indian external debt constituted less than 108 of its capital stock in 1988 . It seems unlikely that Haiti's per capita output would converge instantaneously to that of the U.S. if Haiti adopted U.S. law, giving it the same steady-state income as the U.S., and the U.S. Marine Corps enforced debt contracts. Per capita output was not equalized between countries in the days when loan contracts were enforced by gunboats, and Puerto Rico's output per capita remains substantially below that of the rest of the U.S., despite substantial fiscal transfers.

This paper is related to previous work. Benhabib and Rustichini [1991] discuss how non-exponential depreciation can lead to cycles in investment, as capital is periodically replaced. Pierce [1990] examines the impact of imperfect substitutability between the human capital of young and old 
lawyers on the decision to obtain legal education. He estimates that young and old lawyers are poor substitutes, with an elasticity of substitution of about 0.25 , and develops a rational-expectations model of cycles in the acquisition of human capital in law. We differ from Benhabib and Rustichini in allowing for complementarity between differed vintages of capital and from Pierce in using a general-equilibrium analysis to examine the path of economy-wide, as well as sectoral, human capital. In particular, we argue that there may be cycles in human capital within sectors, and gradual convergence of aggregate human capital.

This paper also follows Chari and Hopenhayn [1991], who show that diffusion of technology will be gradual when there is complementarity between experienced and inexperienced workers in each technology. They solve for the steady-state distribution of workers across various vintages of technology. This paper, on the other hand, focuses on the dynamic path of investment in human capital outside the steady state, and on the determinants of the speed of convergence to the steady state. In fact, transition periods of several generations seem more relevant to the process by which poor countries become rich than to the diffusion of a particular new technology within an advanced country.

The remainder of the paper is organized as follows. In section two, we present a basic, aggregate model with imperfect 
substitutability between the human capital of young and old workers in production. In section three, we examine the movement of human capital at the sectoral level, and in section four we integrate aggregate and sectoral dynamics. In these sections, we identify the parameter values for which there will be cycles in human capital at the sectoral level, and monotonic convergence to the steady state at the aggregate level. In section five, we argue that, for reasonable parameter values, imperfect substitutability of young and old human capital can generate convergence at speeds consistent with those empirically observed by Barro and Sala-i-Martin [1992a] and Dowrick and Nguyen [1989]. Section six concludes with a discussion of implications for investment in human capital, focusing on the case of African countries which have rapidly expanded human capital from a low base.

\section{Aggregate Dymamics}

In this section, we investigate the path of aggregate human capital in a simple model in which young and old human capital are imperfect substitutes in production. We show that if there is complementarity between young and old human capital in the sense that an increase in the supply of old human capital will cause an increase in the wage of young human capital, holding constant the quantities (rather than prices) of other factors, 
then there will be monotonic convergence of aggregate human capital, whereas if there is substitutability, there will be gradually dampening oscillations. This section thus follows the work of Pierce [1990]. In the next section, we show that, if there is sufficient complementarity between goods in consumption, there will be cycles in human capital in individual sectors, even though there is monotonic convergence of aggregate human capital.

\subsection{The Competitive-Eguilibrium Path of Buman Capital}

Consider a small, open economy with a large number of sectors, each containing a large number of perfectly-competitive firms producing a single, non-storable good. There are a'large number of identical workers, each of whom lives for two periods and supplies one unit of labor in each period.

Assume that production in period $t$ depends on three inputs: human capital of the young (those born in period $t$ ); human capital of the old (those born in period $t-1$ ); and a third factor that is in fixed supply for the economy as a whole, and which might represent land or "raw" labor." We normalize the supply of the fixed factor to one. Technology is characterized by the

2 When we calibrate the model in section five, we allow for physical capital, technological progress, and population growth. 
constant returns-to-scale production function:

$$
Y_{t}=f\left(H_{t}, H_{t-1}, L_{t}\right)
$$

where $Y_{t}$ is aggregate production, $H_{\tau}$ is young human capital used in period $t, H_{t-1}$ is old human capital used in period $t$ (as well as young human capital in period $t-1$ ), and $L_{t}=1$ is the quantity of the fixed factor. We assume that $f$ has continuous second derivatives, and that output is increasing and concave in human capital $\left(f_{1}>0, f_{2}>0, f_{11}<0, f_{22}<0\right.$, and $\left.f_{11} f_{22}-f_{12}{ }^{2}>0\right)$ and in the fixed factor. As we shall see below, the cross-partial derivative of the production function with respect to young and old human capital $\left(f_{12}\right)$ is a key quantity, and its sign determines whether the path of aggregate human capital is monotonic or exhibits oscillations.

The supply of human capital is chosen by workers given the expected returns to investment in human capital. While imperfections in international capital markets certainly exist, we shall abstract from them in order to focus on the effect of imperfect substitutability in slowing convergence. Hence we assume that workers can borrow to finance human capital 
investment at a fixed world interest rate, $r{ }^{3}$ subject to a no-

Ponzi-game constraint." Workers have perfect foresight; each

worker chooses a level of human-capital investment when young,

and this determines the human capital he supplies in both periods

of his life. ${ }^{5}$ In equilibrium, the discounted return to human-

3 We have assumed that human capital is financed by borrowing on international capital markets subject to a no-Ponzigame constraint. Assuming altruistic links between generations, the old could finance the education of the young in the steady state. Out of the steady state, when intercountry borrowing is reguired, a generation in a less developed country, when young could borrow from the old of a more developed country, and then, when they were old, repay the loans to the lenders' children. We might, alternatively, suppose that each generation lives for three periods, borrowing to acquire education as "children", and repaying loans when young. This would add an additional interest rate term to equation (2), but otherwise leave our model unchanged.

- Every country will be subject to this no-Ponzi-game constraint because countries that have converged to steady-state levels will be prepared to lend only finite amounts, and any country that had unbounded growth would need to be a net borrower. The presence of the fixed factor implies that if human capital grows faster than the interest rate, then human-capital investment will eventually exceed current output and borrowing must also eventually grow faster than the interest rate. Therefore, the discounted value of human capital must also be non-positive in the limit as $t$ goes to infinity. If utility were concave, and many countries were below the steady-state level of human capital, then we would expect those countries that had already converged or that were closest to the steady state to be net lenders, and those countries that were farthest from the steady state to be net borrowers. The interest rate would be above the level implied by the intertemporal discount rate of households, and would fall as the countries of the world

approached their steady states. Here we focus on the simple case of a small country facing a constant world interest rate.

${ }^{5}$ We assume that workers that workers can invest in education only when young. However, even without this assumption, workers would ordinarily choose to do all their investment when young in any case, so that they could reap the benefits in both periods of their life rather than only in the second period of their life. 
capital investment must equal the cost, which we normalize to one unit of output. That is:

$$
q_{t}^{y}+8 q_{t+1}^{0}=1
$$

where $q_{t}^{y}$ and $q_{t}^{\circ}$ are the wages paid to young and old human capital, and $\delta$ is the value of one dollar one period ahead, which in turn equals $1 /(1+r)$, where $r$ is the world interest rate. The return on human capital when young, plus the discounted return on human capital when old, must equal one, the marginal cost of human capital investment.

Since agents can borrow in perfect capital markets, it is unnecessary to consider agents' intertemporal preferences in analyzing production. They simply maximize the value of wages minus education costs, discounted at the world interest rate, and then allocate consumption over time based on their own intertemporal preferences.

Profit maximization and free entry imply that each factor will be paid its marginal revenue product. Thus the equilibrium condition for human capital investment can be rewritten as the second-order difference equation:

$$
\frac{\partial f\left(H_{t}, H_{t-1}, 1\right)}{\partial H_{t}}+\delta \cdot \frac{\partial f\left(H_{t+1}, H_{t}, 1\right)}{\partial H_{t}}=1
$$

That is, the marginal revenue product of education when young, plus the discounted marginal revenue product when old, must equal 
one, the cost of education. This second-order difference equation defines the path of aggregate human capital. The unique steady-state level of human capital is the value, $\bar{H}$, that solves

$$
f_{1}(\bar{H}, \bar{H}, 1)+\delta f_{2}(\bar{H}, \bar{H}, 1)=1
$$

\subsection{Equivalence to the Social Planner's Problem}

The path of human capital in the decentralized economy will be the same as that chosen by a social planner. To see this, note that a social planner seeking at time to maximize the present discounted value of output net of the cost of education will choose values of $H_{t}, H_{t+1}, H_{t+2}, \ldots$, to solve:

$$
\operatorname{MAX} \sum_{s=0}^{\infty} \delta^{s}\left[f\left(H_{t+a}, H_{t+a-1}, 1\right)-H_{t+a}\right]
$$

subject to a no-Ponzi-game condition on the economy's borrowing from the rest of the world.

Since the social planner's problem is concave, the firstorder conditions are necessary and sufficient for a maximum, given the no-Ponzi-game condition, and the maximum will be unique. The first-order conditions are the same as those given by equation (3), and the no-Ponzi-game condition on the social planner is equivalent to the no-Ponzi-game condition on each agents' borrowing in the competitive equilibrium. Thus the competitive-equilibrium outcome and the solution to the social 
planner's problem are identical; for any positive initial level of human capital of the old, there will be a unique path of aggregate human capital, and along this path, aggregate human capital will converge to its steady-state level."

\subsection{Monotonic versus Oscillatory Convergence}

The path of aggregate human capital converges monotonically or exhibits damped oscillations depending on the sign of the cross-partial derivative, $f_{22}$, that is, on the degree of complementarity between young and old human capital in production. Further, since output is strictly monotonically increasing in the levels of both old and young human capital, income will show the same pattern of convergence as human capital.

Proposition 1: If $f_{12}>0$, then aggregate human capital converges monotonically to the steady state; if $f_{12}<0$, then the path of aggregate human capital exhibits damped oscillations.'

- We thank Kiminori Matsuyama for suggesting this approach to the proof of uniqueness.

7 Whether human capital converges monotonically or exhibits damped oscillations depends on the sign of $f_{12}$ for levels of human capital on the equilibrium path: it is a sufficient, but not a necessary, condition that $f_{12}$ has the same sign for all possible levels of human capital. As we note below, for the CES production function, $f_{12}$ does have the same sign for all levels of human capital. 
Proof: ${ }^{8}$ The social planner's problem can be rewritten as:"

$$
v\left(H_{t-1}\right)=\underset{x}{\operatorname{MAX}}\left[f\left(x, H_{t-1}, 1\right)-x+8 v(x)\right] \text {, }
$$

where $\mathrm{V}\left(\mathrm{H}_{\mathrm{t}-1}\right)$ is the present discounted value of future output net of the cost of investment in human capital. If we define $g\left(x, H_{t-1}\right) \equiv f\left(x, H_{t-1}, 1\right)-x$, then $g(\cdot, \cdot)$ has continuous second derivatives, is strictly concave, and is strictly increasing in $\mathrm{H}_{\mathrm{t}-1}$. Thus, $v(\cdot)$ is continuously differentiable, strictly increasing, and strictly concave. ${ }^{10}$ Now, the first-order condition for the maximization problem is $g_{1}\left(H_{t}, H_{t-1}\right)+\delta v^{\prime}\left(H_{t}\right)=0$, and in the steady-state, $g_{1}(\bar{H}, \bar{H})+\delta v^{\prime}(\bar{H})=0$. Both $g$ and $v$ are concave, so $g_{11}$ and $v^{\prime}$ are negative.

Thus, if $g_{12}>0$, then a higher value of $\mathrm{H}_{\mathrm{t}-1}$ implies a higher value of $\mathrm{H}_{\mathrm{t}}$, and $\mathrm{H}_{\mathrm{t}-1}<\overline{\mathrm{H}} \rightarrow \mathrm{H}_{\mathrm{t}}<\overline{\mathrm{H}}$ and $\mathrm{H}_{\mathrm{t}-1}>\overline{\mathrm{H}} \rightarrow \mathrm{H}_{\mathrm{t}}>\overline{\mathrm{H}}$.

Conversely, if $\mathrm{g}_{12}<0$, then a higher value of $\mathrm{H}_{\mathrm{t}-1}$ implies a lower value of $\mathrm{H}_{\mathrm{t}}$, and $\mathrm{H}_{\mathrm{t}-1}<\overline{\mathrm{H}} \rightarrow \dot{\mathrm{H}}_{\mathrm{t}}>\overline{\mathrm{H}}$ and $\mathrm{H}_{\mathrm{t}-1}>\overline{\mathrm{H}} \rightarrow \mathrm{H}_{\mathrm{t}}<\overline{\mathrm{H}}$. Thus, if $g_{12}\left(H_{t}, H_{t-1}\right)>0$ for all $t$, then $H_{t}$ converges monotonically to $\bar{H}_{;}$and if $g_{12}\left(H_{t}, H_{t-1}\right)<0$ for all $t$, then $H_{t}$ exhibits damped oscillations about $\overline{\mathrm{H}} .{ }^{11}$ Since $g_{12}=\mathrm{f}_{12}, \mathrm{H}_{\mathrm{t}}$ will converge monotonically if $f_{12}$ is positive, and $H_{t}$ will exhibit damped oscillations if $\mathrm{f}_{12}$ is negative.

Note that the production function can be interpreted as incorporating a form of adjustment cost. It can be rewritten in

- We thank Jess Benhabib for suggestions on this proof.

- See Stokey and Lucas [1989], section 4.1.

${ }^{10}$ See Stokey and Lucas [1989], Theorems 4.11, 4.7, and 4.8.

11 To show monotonic convergence, we need to show that if $g_{12}\left(H_{t}, H_{t-1}\right)>0$ for all $t$ and $H_{t-1}>\bar{H}$, then $H_{t-1}>H_{t}>\bar{H}$. We know that $\mathrm{H}_{\mathrm{t}}>\overline{\mathrm{H}}$. Suppose that $\mathrm{H}_{\mathrm{t}} \geq \mathrm{H}_{\mathrm{t}-1}$. Then because the social planner's problem is recursive, $H_{t+1} \geq H_{t}$, and by induction, $\bar{H}<H_{t-1} \leq H_{t} \leq H_{t+1} \leq H_{t+2} \leq$ ... That is, if $\mathrm{H}_{\mathrm{t}} \geq \mathrm{H}_{\mathrm{t}-1}$, then the sequence of values of $\mathrm{H}_{\mathrm{t}}$ would not converge. By an analogous argument, if $\mathrm{H}_{t-1}<\bar{H}$, then $H_{t-1}<\mathrm{H}_{t}<\bar{H}$. Thus, convergence must be monotonic. For the case in which $g_{12}\left(H_{t}, H_{t-1}\right)<0$ for all $t$, we can use a similar argument to show that $H_{t+1}$ is closer than $H_{t-1}$ to $\bar{H}$, so that oscillations are damped all along the equilibrium path. 
terms of young human capital in the current period, $H_{t}$, and the change in human capital between cohorts, $\Delta \mathrm{H}_{\mathrm{t}} \mathbf{B}_{\mathrm{t}}-\mathrm{H}_{\mathrm{t}-1}$, as $\mathrm{E}\left(\mathrm{H}_{\mathrm{t}}, \mathrm{H}_{\mathrm{t}}-\Delta \mathrm{H}_{\mathrm{t}}, 1\right)$. In the absence of adjustment costs, young human capital in period $t$ would jump to the steady-state level $(\bar{H})$, the level at which the marginal benefit from an extra unit of young human capital in period $t$ equals the marginal cost of acquiring human capital. With adjustment costs, the marginal benefits and costs would no longer be equal for the steady-state level of human capital. For example, if $f_{12}>0$ and $H_{t-1}<\bar{H}$ (so that $\Delta H_{t}>0$ ), then $f_{1}$ would be lower than if $H_{t-1}=\bar{H}$, and the marginal benefit of young human capital would be less than the cost. Equilibrium would thus imply a value of $\mathrm{H}_{\mathrm{t}}$ below the steady-state level of human capital. Conversely, if $f_{12}<0$, then $f_{1}$ would be higher than if $H_{t-1}=\vec{H}$, and equilibrium would imply a value of $H_{t}$ above the steady-state level of human capital.

An example of a production function with the properties we have assumed is one that is Cobb-Douglas in the fixed factor and in a CES aggregate of young and old human capital: ${ }^{12}$

$$
f\left(H_{t}, H_{t-1}, L_{t}\right)=A\left[\alpha H_{t}^{1-p}+\beta H_{t-1}^{1-p}\right]^{\frac{1}{2-p}} L_{t}^{1-\theta}, \quad \alpha+\beta=1,
$$

where $p$, the reciprocal of the elasticity of substitution, represents the degree of complementarity between the human capital of the young and that of the old. When $p=0$, they are worthwhile. 
perfect substitutes. Taking the limit as $\rho \rightarrow 1$ gives the CobbDouglas case, and taking the limit as $\rho \rightarrow \infty$ gives a Leontief production function in young and old human capital (that is, they are perfect complements).

For this CES production function, the cross-partial derivative is given by:

$$
f_{12}\left(H_{t}, H_{t-1}, 1\right)=\alpha \beta \theta(\rho-1+\theta) A\left[\alpha H_{t}^{1-\rho}+\beta H_{t-1}^{1-\rho}\right]^{\frac{0}{1-p}-2},
$$

and has the same sign as $p-1+\theta$. Thus, if $p>(1-\theta)$, the share of the fixed factor, then convergence to the steady state will be monotonic. If the initial level of human capital is less than the steady-state level, human capital is monotonically increasing. ${ }^{23}$ If $p=0$, so young and old human capital are perfect substitutes, there will be cycles in human capital. If $p$ $=1$, so the production function is Cobb-Douglas in young and old human capital, there will be monotonic convergence. Young and old human capital are complements within the human capital aggregate, but they are substitutes in that they compete to work with the fixed factor. Thus, the more important the fixed factor

13 In the case of a CES production function, it can also be shown that the growth rate is monotonically decreasing. This means that if human capital starts out below its steady-state level, it will increase generation by generation, gradually getting closer to the steady-state level, but the rate of increase in human capital will slow over time as the steady-state level is approached. Conversely, if the initial level of human capital is greater than the steady-state level, human capital monotonically decreases, and the growth rate monotonically increases. 
(the larger $1-\theta$ ), the more likely young and old human capital are substitutes and the path of human capital exhibits oscillations.

\section{Imperfect Substitutability Between Young and old Buman Capital in Production: Sectoral Dymamics}

In this section we consider the behavior of human capital at the sectoral level. We show that human capital within each sector may cycle relative to that in other sectors even for parameter values that generate monotonic convergence in aggregate human capital. In the next section, we integrate aggregate and sectoral dynamics and show that, for a moderate degree of substitutability, human capital in individual sectors will cycle about a monotonically converging path of aggregate human capital, at least close to the steady state.

Consider a small, open economy with a large number of sectors, each containing a large number of perfectly-competitive firms producing a single, non-storable good. We assume that human capital is sector-specific, and we normalize both the aggregate supply of the fixed factor and the number of sectors to one. ${ }^{14}$ Technology is identical across firms and sectors and is characterized by the constant returns-to-scale production function:

14 We can think of there being a continuum of sectors indexed on the closed interval $[0,1]$. 


$$
y_{f, t}=E\left(h_{y, t}, h_{y, t-1}, I_{y, t}\right),
$$

where $y_{j, t}$ is production of good $j, h_{j, t}$ is young human capital used by sector $j$ in period $t, h_{y, t-1}$ is old human capital used by sector $j$ in period $t$, and $l_{1, t}$ is the guantity of the fixed factor used by sector $j$. We assume that $f$ has the same properties as in section two.

Suppose that agents' instantaneous preferences over the output of the various sectors are identical and have the cobbDouglas form:

$$
\log \left(u_{t}\right)=\sum_{j} \log \left(c_{f, t}\right)
$$

where $c_{j, t}$ is consumption of the good produced by sector $j$. (We present below results for the more general case of a CES utility function, which allows for an arbitrary degree of complementarity between goods.) Given this Cobb-Douglas utility function, we can measure aggregate output, $Y_{t}$, in terms of a Cobb-Douglas index of output in individual sectors:

$$
\log \left(Y_{t}\right)=\sum_{f} \log \left(y_{j, t}\right)
$$

We can think of this index as measuring output in terms of a composite good.

As in the case of aggregate human capital in the previous section, the path of human capital in each sector in the decentralized economy will be the same as that chosen by a social 
planner. ${ }^{15}{ }^{36}$ The social planner will choose values of $\mathbf{h}_{\text {y.t. }}$ to maximize the present discounted value of output net of the cost of education, that is, to solve:

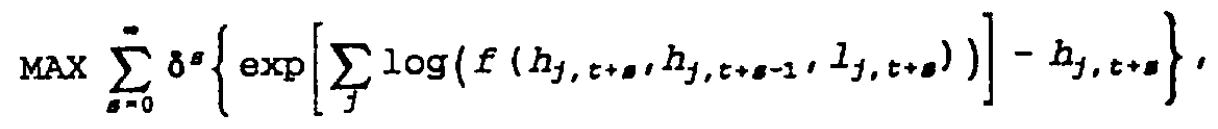

subject to a sequence of constraints on the fixed factor, $\sum_{\text {s }}$ $1_{1, t+s} \leq 1$ for $s=0,1,2, \ldots$, and a no-Ponzi-game condition on the economy's borrowing from the rest of the world.

The first-order condition for the social planner's problem is :

$$
\frac{\partial y_{f, t}}{\partial h_{j, t}} \cdot \frac{Y_{t}}{y_{f, t}}+\delta \cdot \frac{\partial y_{f, t+1}}{\partial h_{f, t}} \cdot \frac{Y_{t+1}}{y_{f, t+1}}=1
$$

This implicitly defines $h_{j . t}$, the path of human capital in sector $j$, given aggregate output $\left(Y_{t}\right)$ and the amount of the fixed factor in sector $j$.

Since the social planner's problem is concave, the firstorder conditions are necessary and sufficient for a maximum, given the no-Ponzi-game condition, and the maximum is unique. For any positive initial level and distribution of human capital

15 Strictly, this is true up to a subset of sectors of measure zero, but this of technical, rather than economic. relevance.

16 The argument is the same as in the previous section: the first-order conditions for the social planner's problem are the same as the human-capital-investment equilibrium condition in the competitive economy, and the no-Ponzi-game conditions facing each agent are equivalent to the one facing the social planner. 
of the old, there will be unique paths of human capital in each sector, and along these paths, sectoral human capital will converge to the steady-state level.

Under the assumptions that preferences are Cobb-Douglas across goods, and the production function has the CES form,

$$
f\left(h_{f, t}, h_{f, t-1}, l_{f, t}\right)=A\left[\alpha h_{f}^{1-p}+\beta h_{f}^{1-p}\right]^{\frac{1}{1-T}} l_{f, t}^{1-\theta}, \quad \alpha+\beta=1,
$$

and is the same in all sectors, whether human capital in each sector oscillates relative to other sectors depends on the sign of $E_{12}-E_{1} E_{2} / f$.

Proposition 2: If the sign of $f_{12}-f_{1} f_{2} / f$ is the same for all values of young and old human capital, then a sector that uses more human capital of generation $t-1$ than another sector will also use more human capital of generation $t$ if $f_{12}-f_{1} f_{2} / f>0$; and a sector that uses more human capital of generation $t-1$ will use less human capital of generation $t$ if $f_{12}-f_{1} f_{2} / f<0$.

Preof: With Cobb-Douglas preferences and the CES production function, demand for the fixed factor is independent of the level of human capital in the sector, ${ }^{17}$ and we can follow the same approach as in the proof of Proposition 1. The social planner's problem for sector $k$, given the path of aggregate output, can be written as:

17 This result does not hold for all production functions that exhibit constant returns-to-scale in young and old human capital and the fixed factor. 


$$
v_{k, t}\left(h_{k, t-1}\right)=\underset{x}{\operatorname{MAx}}\left\{\exp \left[\sum_{f} \log \left(y_{j}, t\right)\right]-x+8 v_{k, t+1}(x)\right\},
$$

where $y_{k, t}=f\left(x, h_{k, t-1}, 1\right)$ and the time subscript on the value function indicates that it is conditional on the path of aggregate output from the current generation forward. ${ }^{18}$ The first-order condition for the maximization problem is :

$$
f_{1}\left(h_{k, t}, h_{k, t-1}, 1\right) \cdot \frac{Y_{t}}{f\left(h_{k, t}, h_{k, t-1}, 1\right)}-1+8 v_{k, t+1}^{\prime}\left(h_{k, t}\right)=0 \text {. }
$$

If the derivative of the term $f_{1} Y_{t} / f-1$ with respect to $h_{k, t-1}$ is positive, then lowering $h_{k, t-1}$ while holding $h_{x, t}$ fixed would make the left-hand side of the equation less than 0 . since the left-hand side is decreasing in $h_{k, t}$, this implies that a sector with less human capital of generation $t-1$ would also have less human capital of generation $t$. Conversely, if the derivative is negative, a sector with less human capital of generation $t-1$ will have more human capital of generation $t$. Now, the derivative is $Y_{t}\left(f_{12} f-f_{1} f_{2}\right) / f^{2}$. so its sign is determined by the sign of $f_{12}-$ $\mathrm{f}_{1} \mathrm{f}_{2} / \mathrm{f}$.

If the amount of young human capital demanded by each sector is increasing in the amount of old human capital used by the sector, then a sector that has higher human capital relative to another sector in one period will have higher human capital in the next and all subsequent periods. As in the aggregate case, demand for young human capital is influenced by the amount of old human capital through the degree of complementarity between young and old human capital in production, which is reflected by $f_{12}$.

18 Since each sector's demand for labor is independent of its level of human capital in this case, and the number of sectors is normalized to one, each sector's use of labor must be $1_{j, t}=1$. 
However, at the sectoral level, demand for young human capital is also influenced by the amount of old human capital through its effect on the price of the sector's output, which is reflected by $-\mathrm{f}_{1} \mathrm{f}_{2} / \mathrm{f}$.

Thus, if $f_{12}-f_{1} f_{2} / f$ is positive, then the rank order of human capital across sectors will be preserved over time. If, on the other hand, $f_{12}-f_{1} f_{2} / f$ is negative, then the rank order of human capital across sectors will be reversed each period. ${ }^{19}$ Thus, like Pierce [1990], we find possible cycles at the sectoral level. If human capital is high in generation $t-1$ and young and old human capital are substitutes, then generation $t$ has little incentive to accumulate human capital. But, if generation $t$ chooses low human capital, that will provide generation $t+1$ with an incentive to choose high human capital, and a new cycle will begin. For example, a large number of people entered academics after World War II, so few people entered in subsequent decades. Now that a large number of professors are retiring, more people are again entering academics. In the case of a tradable good, these dynamics will take place at the level of the world economy, whereas in the case of non-tradable goods they will take place within each national economy.

Note that for the CES production function, $f_{12}-f_{1} f_{2} / f$ has the same sign as $p-1$. Thus, if the degree of complementarity between

19 If $f_{12}-f_{1} f_{2} / f$ equals zero, then after the initial period, human capital will become identical across sectors. 
young and old human capital is greater than one, then the rank order of human capital across sectors will be preserved, and if the degree of complementarity is less than one, the rank order will be reversed each period.

Table 1 summarizes the behavior of sectoral and aggregate human capital for various values of $\rho$, the degree of complementarity between young and old human capital, relative to $\theta$, the share of capital.

Table 1. Sectoral and Aggregate Dynamics for Cobb-Douglas Preferences

\begin{tabular}{||c|c|c|}
\hline$\rho<1-\theta$ & Sectoral Dynamics & Aggregate Dynamics \\
\hline $1-\theta<\rho<1$ & oscillations & oscillations \\
\hline$\rho>1$ & oscillations & $\begin{array}{c}\text { monotonic } \\
\text { convergence }\end{array}$ \\
\hline
\end{tabular}

For a more general, CES utility function of the form

$$
u_{t}=\sum_{f} \frac{c_{f, \eta}^{1-\eta}-1}{1-\eta}
$$

where $\eta$ measures the degree of complementarity between goods in consumption, the rank order of human capital across sectors will be reversed if $\rho<\eta /[\theta+\eta(1-\theta)]$. Thus, rank reversal is more likely if goods are close complements in consumption ( $\eta$ is 
high). ${ }^{20}$ When good $j$ is a close complement for other goods $(\eta$ is high), production of good $j$ will move closely with the path of aggregate production so that a relatively low level of human capital in sector $j$ in one generation will be followed by a high level of human capital relative to other sectors in the next generation. ${ }^{21}$

our results should not be taken to imply that human capital either converges monotonically in every sector, or oscillates in every sector. Most sectors' goods may be reasonably close substitutes ( $\eta$ low), and young and old human capital may be complementary for most sectors ( $p$ relatively high), so that human capital converges monotonically in these sectors, but human capital may exhibit oscillations in those sectors in which young and old human capital are less complementary, or whose output is strongly complementary with other goods in the economy.

Table 2 summarizes the behavior of sectoral and aggregate human capital for various values of $\rho$ in the case of general CES

20 This can be shown using the same approach as in the proof of Proposition 2. With non-Cobb-Douglas preferences, however, the use of the fixed factor by a sector depends on the level of human capital in the sector, so it is necessary to solve for the use of the fixed factor in terms of human capital and the wage to the fixed factor. Details are available from the authors.

21 The condition for damped oscillations can be met only if $\rho<1 /(1-\theta)$, that is if young and old human capital are sufficiently close substitutes in production of good $j$. If they are very close complements, then each generation will choose a level of human capital close to that of the previous generation, even if that level is considerably different from the levels of human capital in other sectors. 
preferences between goods with degree of complementarity indexed by $\eta$.

Table 2. Sectoral and Aggregate Dymamics for CES Dtility

\begin{tabular}{|c|c|c|}
\hline & $\eta<\rho \theta /[1-\rho(1-\theta)]$ & $\eta>\rho \theta /[1-\rho(1-\theta)]$ \\
\hline$\rho<1-\theta$ & $\begin{array}{c}\text { Sector: monotonic } \\
\text { Aggregate: } \\
\text { oscillations }\end{array}$ & $\begin{array}{c}\text { Sector: } \\
\text { oscillations } \\
\text { Aggregate: } \\
\text { oscillations }\end{array}$ \\
\hline$\rho>1-\theta$ & $\begin{array}{c}\text { Sector: monotonic } \\
\text { Aggregate: } \\
\text { monotonic }\end{array}$ & $\begin{array}{c}\text { Sector: } \\
\text { oscillations } \\
\text { Aggregate: } \\
\text { monotonic }\end{array}$ \\
\hline
\end{tabular}

We do not know the values of the parameters, but the absence of cycles at the aggregate level indicates that $\rho$ is greater that 1- $\theta$. Evidence of cycles within at least some sectors from Freeman [1975a, 1975b, 1976] suggests that $\eta$ is greater than $\rho \theta /[1-\rho(1-\theta)]$ in those sectors.

\section{Integrated Sectoral and Aggregate Dymamics Near the Steady- state}

It is possible to analyze sectoral and aggregate dynamics simultaneously by linearizing around the steady state. We consider the case of the CES production function and begin by aggregating across sectors and examining the equilibrium path of 
human capital for the economy as a whole. Then we show that the paths of sectoral human capital can be interpreted as movements about the path of aggregate human capital.

The equilibrium condition for human capital in each sector, given aggregate output at $t$ and $t+1$, is given by equation (13). If we use the definition of the aggregate output index in equation (11), and take a first-order Taylor series approximation of this first-order condition, we get a linear second-order difference equation in $\hat{h}_{j, t}$ and $\hat{H}_{t}$, the deviations of sectoral and aggregate human capital from their steady-state levels:

$$
h_{f, t+1}-c_{\mathrm{sec}} \hat{h}_{y, t}+\frac{1}{\delta} \hat{h}_{f, t-1}+\frac{\theta}{\rho-1} \cdot\left[\hat{h}_{f, t+1}+c_{e g g} \hat{H}_{f, t}+\frac{1}{\delta} \hat{A}_{f, t-1}\right]=0 ，
$$

where

$$
c_{\mathrm{sec}}=\frac{\alpha \beta p(1+\delta)+\left(\alpha^{2}+\beta^{2} 8\right)}{\alpha \beta \delta(p-1)}
$$

and $c_{n g g} \equiv\left(\alpha^{2}+\delta \beta^{2}\right) /(\alpha \beta \delta)$. Summing over sectors eliminates the terms in $\hat{h}$, the sectoral deviations, and gives a difference equation that defines the path of deviations of aggregate human capital from the steady-state level:

$$
A_{t+1}-\left[\frac{\alpha \beta p(1+\delta)+\left(\alpha^{2}+\beta^{2} \delta\right)(1-\theta)}{\alpha \beta \delta(\rho-1+\theta)}\right] A_{t}+\frac{1}{\delta} A_{t-1}=0 .
$$

Since this is a second-order, linear-homogeneous difference equation, its solution has the form $B_{1}\left(\Lambda_{1}\right)^{t}+B_{2}\left(\Lambda_{2}\right)^{t}$, where $\Lambda_{1}$ and $\Lambda_{2}$ are the roots of the corresponding characteristic equation, and $B_{1}$ and $B_{2}$ are constants determined by the initial value of 
aggregate human capital and the condition that human capital must converge to its steady-state level. The product of the roots is the coefficient on $\hat{\mathrm{H}}_{\mathrm{t}-1}$, that is, $1 / \delta>1$. Thus the two roots have the same sign, and one root $\left(\Lambda_{2}\right.$, say) will be greater than one in absolute value. Convergence requires that $\Lambda_{1}$ is less than one in absolute value, and that the coefficient on the other root $\left(B_{2}\right)$ is zero. The sum of the roots is the negative of the coefficient on $\hat{H}_{t}$. Thus, $\Lambda_{1}$ will be positive if the term in square brackets in $(20)$ is positive. That is, as we found before, convergence of aggregate human capital will be monotonic if $p>1-\theta$. Conversely, human capital will exhibit damped oscillations about its steady-state level if $p<1-\theta$.

Substituting the solution for the path of aggregate human capital $\left(\mathrm{B}_{1} \Lambda_{1}{ }^{\mathrm{C}}\right)$ back into equation (18) gives a second-order difference equation in deviations of sectoral human-capital from the steady-state level:

$$
\hat{h}_{y, t+1}-c_{a e c} \hat{h}_{y, t}+\frac{1}{\delta} \hat{h}_{f, t-1}+\frac{\theta}{p-1} \cdot\left[\Lambda_{1}+c_{a g g}+\frac{1}{\delta \Lambda_{1}}\right] B_{1} \Lambda_{1}^{t}=0 .
$$

This has solution $\hat{h}_{j, t}=b_{j} \lambda_{j}{ }^{t}+B_{1} \Lambda_{1}{ }^{t}$, where $\lambda_{j}$ is the smaller root in absolute value of the characteristic equation corresponding to the left-hand side of equation (21), $b_{f}$ is determined by the initial level of human capital in sector $j$ relative to aggregate human capital, and $\sum_{j} b_{j}=0$. Thus, close to the steady state, the path of human capital in any sector is equivalent to the sum of two terms: one in $\Lambda_{1}$ representing the path of the aggregate 
economy; and one in $\lambda$, representing the path of the individual sector relative to aggregate human capital.

Human capital in sector $j$ will exhibit damped oscillations about the path of aggregate human capital if $\lambda_{y}$ is negative. For Cobb-Douglas preferences, this occurs when $p<1$. Thus, when 1$\theta<p<1$, close to the steady state, human capital in each sector will exhibit damped oscillations about a path of aggregate human capital that is converging monotonically to its steady-state level. This strengthens our earlier global result that the rank order of human capital across sectors will be reversed each period if $p<1$.

For the more general, CES utility function, human capital in sector $j$ exhibits damped oscillations if $p<\eta /[\theta+\eta(1-\theta)]-$ that is, if $\eta>p \theta /[1-p(1-\theta)]$. Thus, if good $j$ is sufficiently complementary with other goods in the economy and if young and old human capital are not too complementary in production - such as in the case of log utility - then there will be a unique sequence of human-capital levels in sector $j$ that converge to the steady-state level, but that exhibit damped oscillations about the steady state. ${ }^{22}$ This is illustrated in Figure 1.

It is difficult to work out analytically what happens further from the steady state, but we conjecture that the further from the steady state, the more aggregate production is reduced

22 This implies that total human capital in the sector also exhibits damped oscillations. 
by the imbalance in human capital between sectors. Thus, far from the steady state, the aggregate growth rate will be boosted by the reduction in imbalances between sectors.

Note that for this be consistent with to explain the path of consumption, as well as production, capital markets cannot be completely perfect. If they were perfect, poor countries would want to borrow to smooth their consumption. In reality, it may be difficult to borrow for consumption purposes and to pass the debts on to one's children. If enforcement mechanisms rely on trade sanctions that reduce income, they may be ineffective in enforcing repayment of consumption loans. Habit formation in consumption might also help explain why countries spread consumption growth over time, rather than borrowing to raise consumption instantaneously to its steady-state level. In addition to its implications for convergence, the model carries implications for relative wages and for migration. Since human capital is scarcer in poor regions, and capital earns the same return everywhere, unskilled labor will be relatively abundant in poor regions and will therefore earn a lower return. Furthermore, since human capital increases more rapidly in poor regions than in rich ones, the human capital of the young will be relatively abundant in poor countries, and hence, will earn a lower return. The model is thus consistent with migration of unskilled labor and young human capital from poor countries to rich countries. The model also predicts that old human capital 
will be scarce in poor countries, and will earn a high return. Thus old educated people will have an incentive to migrate from rich to poor countries. To some extent, this is observed. Multinationals post experienced older managers from developed countries in developing countries, and some people emigrate from developing countries when young and return when old. In the real world, however, the tendency for old educated people to migrate to poor countries is mitigated in two ways. First, older migrants would leave behind families and established networks of business and social contacts and would need to adjust to a different culture. Second, the reason that old human capital is highly valued is because old workers are needed to work with young workers, but cultural and language differences with young workers might make this difficult.

Nevertheless, the implication that old human capital will earn a higher absolute wage in poor countries than rich countries seems an unattractive feature of this model. However, models of capital-market imperfections, such as Barro, Mankiw, and Sala-iMartin [1992], yield the similar implication that educated workers will earn a higher absolute amount in poor countries than in rich countries.

\section{Convergence in a Generalized sodel}

In this section, we extend the model of section two in order 
to determine speeds of convergence of young and old human capital. We extend the CES production function to allow for physical capital, technological progress, and population growth. Then, we examine how the speed of convergence is related to the parameters of the model. In particular, we show how the speed of convergence in general decreases as the degree of complementarity between young and old human capital (p) increases, and as the share of human capital in production $(\theta)$ increases relative to the share of raw labor.

In extending the model, we identify the fixed factor with raw labor and we assume that the number of workers born each generation grows at a constant rate, $n$, so that $L_{c}=L_{0} n^{c}$. We suppose that there is labor-augmenting technological progress, at intergenerational rate $g$, and we introduce physical capital $\left(\mathrm{K}_{\mathrm{t}}\right)$, which we assume is rented on the world capital market at the constant rate $r+d$, where $r$ is the world interest rate, and $d$ is the rate of depreciation of physical capital.

With these extensions, the aggregate production function for goods in the economy is given by:

$$
Y_{t}=A\left[\alpha H_{t}^{1-p}+\beta H_{t-1}^{1-p}\right]^{\frac{0}{1-p}} K_{t}^{\gamma}\left(L_{0} n^{t} g^{t}\right) \cdot \theta+\gamma+\phi=1,
$$

where $H_{t}$ represents young human capital in period $t$, and $H_{t-1}$ is old human capital in period $t$. As before, the competitiveequilibrium outcome is the same as the solution to the social planner's problem. The social planner chooses a path of human 
capital to solve

$$
\operatorname{MAX} \sum_{i=0}^{\infty} 8 \cdot\left[Y_{t+0}-H_{t+a}\right]
$$

This yields the first-order condition:

$$
\alpha\left[\alpha Z_{t}^{1-p}+\beta\left(\frac{Z_{t-1}}{n g}\right)^{1-p}\right]^{\nu-1}+\beta \delta(n g)^{p}\left[\alpha Z_{t+1}^{1-p}+\beta\left(\frac{Z_{t}}{n g}\right)^{1-p}\right]^{\gamma-1}=\left[\frac{I+d}{\gamma}\right]^{\frac{I}{1-\gamma}} \frac{Z_{t}^{p}}{\theta A^{\frac{1}{1-\gamma}}},
$$

where $Z_{t} \equiv H_{t} /\left(L_{0} g^{t} n^{t}\right)$ is aggregate human capital per efficiency unit of labor, and $v \equiv \theta /[(1-\rho)(1-\gamma)]$.

As in the case of the basic model of section two, for each initial level of human capital per efficiency unit there is a unique path of human capital that converges to the steady-state level, and this path will be chosen by the economy. ${ }^{23}$ The path is monotonic if $\rho>\phi /(\theta+\phi)$, and exhibits damped oscillations if $\boldsymbol{\rho}<\boldsymbol{\phi} /(\boldsymbol{\theta}+\boldsymbol{\phi})$. Note that $\phi /(\boldsymbol{\theta}+\boldsymbol{\phi})$ is the share of the fixed factor relative to the fixed factor plus human capital. Thus convergence is "more likely" to be monotonic if the share of the fixed factor is small, and will always be monotonic when $\rho$ is one (or greater). The share of physical capital does not affect the speed of convergence, because physical capital adjusts to the

23 The argument is the same as for the economy in section two. The conditions for the competitive equilibrium are the same as for the social planner's problem, which is concave and thus has a unique solution. 
level of human capital. ${ }^{24}$

We can calibrate the model and compare the results with empirically observed rates of convergence. In calibrating the model, our aim is to illustrate some of the effects and get a sense of their quantitative magnitude, rather than to test the model. We calibrate the model assuming no capital-market imperfections and no adjustment costs other than those created by intergenerational complementarities. In reality convergence will be further slowed by these other factors as well. The most plausible configurations of parameter values are therefore not ones that generate the speeds of convergence observed empirically, but values that generate somewhat faster convergence.

To determine rates of convergence close to the steady state, we derive a Iinearized version of the model using the same procedure as in section four. Close to the steady state, deviations of human capital from their steady-state level $\left(Z_{t} \equiv Z_{t}-\right.$ z) satisfy the second-order difference equation:

$$
\hat{Z}_{t+1}-\frac{\frac{\phi(n g)^{p}}{\theta+\phi}\left[\alpha^{2}(n g)^{1-2 p}+\beta^{2} \delta\right]+\alpha \beta \rho[1+\delta n g]}{\alpha \beta \delta n g\left[\rho-\frac{\phi}{\theta+\phi}\right]} z_{t}+\frac{1}{\delta n g} z_{t-1}=0
$$

The solution to the difference equation has the form $Z_{t}=B \Lambda^{t}$. If

This is also true in Barro, Mankiw, and Sala-i-Martin Convergence July 27, 1994 
young and old human capital are close substitutes (p is small), then $\Lambda$ is negative and human capital per efficiency unit will exhibit damped oscillations about the steady-state level; if young and old human capital are sufficiently complementary $(\rho>\phi /(\theta+\phi))$, then $\Lambda$ is positive and human capital will converge monotonically to the steady-state level. We discuss the relationship between convergence and the parameters in our model in greater detail below.

We adopt the following baseline values for parameters: We assume a population growth rate of $1 \%$ a year, a productivity growth rate of $2 \%$ a year, and a discount rate of $4 \%$ a year. We assume people join the labor force at 19 and leave at 65 , spending the first half of this period as young workers and the second half as old workers, so the length of a period is 23 years. The share of physical capital $(\gamma)$ is assumed to be 0.3 . The relative weights of old and young human capital ( $\alpha$ and $\beta$ ) are both set to 0.5 . This choice is somewhat arbitrary, but it is consistent with empirical observation of higher wages for older workers, since in the presence of population growth and technological change, old human capital is scarcer than young human capital.

The two most important free parameters are $p$, the degree of complementarity between young and old human capital, and $\theta$, the share of human capital. Although Murphy and Welch [1992] have attempted to estimate some elasticities of substitution (1/p) 
between different types of labor, as noted in section one, their results are sensitive to the specific assumptions that they make. The minimum wage has been used to calculate the share of human capital [Barro and Sala-i-Martin, 1992b], but this provides only a lower bound since even workers with no formal education have human capital in the form of training from their parents. Barro and Sala-i-Martin argue that a total share for physical and human capital of about 0.8 enables a closed-economy, neoclassical growth model to generate observed speed of convergence, but this gives no guidance as to the appropriate share of capital in this adjustment-cost model. The fact that we observe a wide range of income levels in the world points to a high share of accumulable factors, which would allow small differences in tax rates or corruption, for example, to produce large differences in steadystate income.

In the top panel of Table 3 below, we show the speeds of convergence close to the steady state of human capital and income (both per efficiency unit of labor) for a range of plausible values of the share of human capital $(\theta)$, and the degree of complementarity (p). ${ }^{25}$ Recall that the share of physical capital is assumed to be .3 , so that the share of the fixed factor equals

25 The speed of convergence is the percentage of the difference between human capital per efficiency unit of labor, $z_{t}$, and its steady-state level, $\bar{z}$, or between income per efficiency unit of labor and its steady-state level, that is eliminated between periods $t$ and $t+1$, expressed at an annual rate. 
7- $\theta$. The speed of convergence falls as the share of human capital ( $\theta$ ) rises, and as young and old human capital become stronger complements ( $p$ increases).

Table 3: Speed of Convergence in $*$ per Year for various values of $p$ and $\theta$

\begin{tabular}{|c|c|c|c|c|c|}
\hline & $\theta=0.4$ & $\theta=0.5$ & $\theta=0.6$ & $\theta=0.65$ & $\theta=0.69$ \\
\hline \multicolumn{6}{|c|}{$\begin{array}{c}\text { Speed of Convergence Near Steady State for Human } \\
\text { Capital and Income }\end{array}$} \\
\hline $\begin{array}{l}p=0.5 \\
p=1.0 \\
p=1.5\end{array}$ & $\begin{array}{r}12.93 \\
6.10 \\
4.58 \\
\end{array}$ & $\begin{array}{l}7.90 \\
4.57 \\
3.51 \\
\end{array}$ & $\begin{array}{l}4.68 \\
2.91 \\
2.27 \\
\end{array}$ & $\begin{array}{l}2.99 \\
1.88 \\
1.45 \\
\end{array}$ & $\begin{array}{l}1.06 \\
0.63 \\
0.47\end{array}$ \\
\hline \multicolumn{6}{|c|}{$\begin{array}{c}\text { Speed of Convergence at } 508 \text { of Steady-State for } \\
\text { Human Capital }\end{array}$} \\
\hline $\begin{array}{l}p=0.5 \\
p=1.0 \\
p=1.5\end{array}$ & $\begin{array}{r}12.11 \\
5.24 \\
3.89\end{array}$ & $\begin{array}{l}7.13 \\
3.86 \\
2.95\end{array}$ & $\begin{array}{l}4.05 \\
2.40 \\
1.86\end{array}$ & $\begin{array}{l}2.51 \\
1.52 \\
1.17\end{array}$ & $\begin{array}{l}0.84 \\
0.48 \\
0.35\end{array}$ \\
\hline \multicolumn{6}{|c|}{$\begin{array}{c}\text { Speed of Convergence at } 508 \text { of steady-State Human } \\
\text { Capital for Income }\end{array}$} \\
\hline $\begin{array}{l}p=0.5 \\
p=1.0 \\
p=1.5\end{array}$ & $\begin{array}{c}\star \\
5.04 \\
4.32\end{array}$ & $\begin{array}{c}\star \\
3.62 \\
3.15\end{array}$ & $\begin{array}{l}3.19 \\
2.17 \\
1.81\end{array}$ & $\begin{array}{l}2.01 \\
1.33 \\
1.08\end{array}$ & $\begin{array}{l}0.70 \\
0.43 \\
0.32\end{array}$ \\
\hline
\end{tabular}

* Initial income is not defined because the speed of convergence of
human capital is so high that it implies a negative value for old human capital.

Away from the steady state, the linearizations are less accurate, and the speeds of convergence of income and human capital are no longer identical. Simulations using multiple shooting suggest that convergence of human capital is a little slower away from the steady state. For example, the middle and 
bottom panels of Table 3 show rates of convergence of young human capital and income, respectively, for human capital per efficiency unit at 50 percent of the steady-state level. ${ }^{26}$

It is possible to make some general observations about the relationship between the rate of convergence and the values of the parameters in our model. ${ }^{27}$ First, the rate of convergence slows as the relative share of human capital compared to the fixed factor $\theta /(\theta+\phi)$ rises, and the rate of convergence does not depend on the share of physical capital, $\gamma$. The intuition for this can be seen by considering the human capital decision of the young. To the extent that the share of raw labor, $\phi /(\boldsymbol{\theta}+\boldsymbol{\phi})$, is high, the relative returns from choosing a level of human capital close to the steady-state level of human capital are also high, and convergence to the steady state will be fast.

In general, the rate of convergence declines monotonically in the degree of complementarity, but it need not do so. It is easiest to consider the effect of $\rho$ on convergence by first considering the case without population growth or technological change. In this case, we get the intuitive result that, the greater the degree of complementarity between young and old human capital, the more the young tend to choose a level of human

26 Income is defined as gross output less the sum of the rental cost of physical capital and the cost of education during the period.

27 We merely state the results and discuss the intuition here. Details of the derivations are available from the authors. 
capital close to that of the old, and the slower is convergence. For $\mathrm{ng}>1$, however, the speed of convergence increases with $p$ at high levels of $p$. With $n g>1$, the effective size of each cohort is larger than that of the previous cohort. To take an extreme example, if $p$ were infinite, and the production function were Leontief in young and old human capital, then in the steady state each cohort's human capital would be in excess supply and earn nothing when it was young, but would appropriate all returns to human capital when it was old. Hence the optimal choice of human capital for the young would not be affected by the level of human capital for the old, and the economy would move to the steady state immediately. In general, for $\mathrm{ng}>1$, there will be some level of $p$ that minimizes the speed of convergence. For our baseline parameter values, this level of $p$ is between 2.9 and 3.1. With higher values of $\mathrm{n}$ and $\mathrm{g}$, a smaller value of $p$ would minimize the speed of convergence.

Convergence is faster when either $\alpha$, the relative share of young human capital, or $\beta$, the relative share of old human capital, is close to one, and slower when the relative shares are more equal. If, for example, the share of young human capital was one, any cohort's return to human capital would be received entirely when young, and the return would be independent of the human capital of the previous cohort, so the human capital investment would move straight to the steady-state level. A similar argument applies when $\beta=1$. In the simulation reported 
above, the rate of convergence is minimized for a around 0.39 when $p$ is $0.5,0.47$ when $p$ is 1 , and 0.64 when $p$ is 2 . However, the speeds of convergence for these values of a are not markedly different from those in the simulations reported.

The effects of changes in population and productivity growth, $\mathbf{n}$ and $\mathrm{g}$, on convergence are identical but neither they, nor the effect of changes in the value of income one period ahead, $\delta$, are easy to sign analytically. However, for the parameter values we have chosen, the rate of convergence increases as $\mathrm{n}$ and $\mathrm{g}$ increase, and as 8 increases (and $r$, the interest rate, falls.) For example, when $p=1, \theta=0.6$, and $r=48$ (as in Table 3 ), the speed of convergence close to the steady state is 2.918 each year. If $r=28$, the speed of convergence would be $3.90 \%$ each year, and if $r=68$, the speed of convergence would be 2.258 .

Since the open-economy, neoclassical model without adjustment costs predicts immediate convergence, the results we report above can be taken as indicating that adjustment costs created by complementarity between old and young human capital significantly slow convergence.

It is instructive to compare these speeds of convergence to those found in empirical research. Barro and Sala-i-Martin argue that U.S. states may be taken as having similar steady states, and find that they converge at around 28 a year. OECD countries converge at around 18 a year unconditionally [Dowrick and 
Nguyen, 1989]. Barro and Sala-i-Martin interpret this lower speed of convergence as indicating some difference in steady states among these economies, but it could also be due to lesser mobility of capital (in the neoclassical model) or labor (in this model) between countries than within countries. Countries of the world do not converge unconditionally, and under either our model or a closed-economy version of the neoclassical model, this would be interpreted as evidence that they do not have the same steady states. Barro and Sala-i-Martin find that countries of the world converge at around 28 per year after controlling for human capital, and interpret human capital as a proxy for steady state income. However, if human capital was interpreted as the value of a state variable, conditional convergence would be difficult to interpret within the neoclassical model. Conditional convergence might be at least qualitatively consistent with the model of this paper, since it predicts that countries that have rapidly growing human capital would have high ratios of human capital to income. This could cause a growth regression to generate a negative coefficient on income and a positive coefficient on human capital.

\section{Conclusion}

We have argued that complementarity between the human capital of young and old workers can explain why output per 
capita does not converge instantaneously across countries. We have concentrated on complementarity that arises from young and old workers' playing different roles in the production process, but complementarity also arises because workers with extensive formal education receive more on-the-job training from old workers. Under either type of complementarity, each generation's optimal human capital depends on the human capital of previous and succeeding generations, and there is a unique path to the steady-state level of human capital along which each generation's human capital is optimal given that of all other generations. For a moderate degree of substitutability, the path of human capital within individual sectors, such as law or academics, will display gradually dampening cycles. Aggregate human capital, however, will converge to the steady state monotonically. A linearized version of the model can generate empirically relevant speeds of convergence.

Although this model is similar to models of credit constraints, such as Barro, Mankiw, and Sala-i-Martin [1992], in predicting slow convergence, it is driven by a fundamentally different mechanism. Under credit constraints, growth is slowed by the desire to smooth consumption; whereas under imperfect substitutability, growth is slowed by a form of adjustment costs in production. ${ }^{28}$

\footnotetext{
28 We have considered adjustment costs in a decreasing returns-to-capital case, but in Kremer and Thomson (1992) we (continued...) 
The welfare implications of imperfect substitutability between young and old human capital differ sharply from those of imperfect credit markets. Models driven solely by imperfect credit markets imply there are large potential welfare improvements from policies that relax credit constraints and allow a rapid expansion of education. However, the view that credit constraints are all that prevent instantaneous convergence of human capital and per capita output between rich and poor countries is difficult to reconcile with the poor performance of many countries with substantial oil and mineral wealth. Moreover, the experience of many African countries suggests that there may be substantial adjustment costs in rapidly expanding education. Starting from a low base, sub-Saharan Africa had a much higher growth rate of education than developing countries as a whole. From 1965 to 1990 primary enrollment as a percentage of the relevant age group increased 658 in sub-Saharan Africa, compared to a 338 average among developing countries. Secondary enrollment increased 8.5 times, compared to 2.75 times in developing countries as a whole. Tertiary enrollment grew 1008 as opposed to 408 in developing countries as a whole [World Bank 1987, 1993]. Yet, Africa's rate of economic growth has been dismal relative to other developing countries.

\footnotetext{
${ }^{28}(\ldots$ continued)

examine the case in which there are constant returns to physical and human capital taken together. In this case, adjustment costs lead to a steady-state growth rate rather than a steady-state level of income.
} 
Kenya provides an instructive example. Some 30,000 students were enrolled in secondary schools in 1963, on the eve of independence. Ten years later the number had increased more than five-fold, to 175,000, and by 1978, Kenya had 15 times the number of secondary school students it had 15 years earlier [Killick, 1981]. Higher education grew even more dramatically: in 1963, 370 Kenyans were enrolled in East African universities; twelve years later there were 5104, for an annual growth rate of $\mathbf{2 4 . 5 8}$ [Lockhart, 1981] . By 1976, 128 of measured GDP and nearly 308 of Kenya's population were students [Todaro, 1981]. According to government figures, 308 of the national budget went to education [Lockhart, 1981]. ${ }^{29}$ Yet with this tremendous increase in education came an increase in unemployment among the educated. At the beginning of the 1980's the education system was producing 200,000 school leavers a year, including primary-school graduates, but employment in the modern sector of the economy was expanding by only about 40,000 jobs a year [Lockhart, 1981]. At least according to some researchers, there was little evidence that education significantly improved productivity for those remaining in agriculture [Hopcraft, 1974]. As education expanded, the estimated rate of return dropped. In a study of over 4000 workers that controlled for ability as measured by test scores, Thias and Carnoy [1972] found that the social return to

29 The World Bank reports a 208 share of education in government expenditure, however. 
primary education dropped steadily from 148 in 1960 to 58 in

1966. (This may overstate the true decline, however, since a

large part of the calculated decline is due to increasing

unemployment, which was also affected by business cycle

factors. ${ }^{30}$ )

The experience of Africa and of mineral-rich countries

suggests that much of the new growth literature may have

exaggerated the importance of credit-market imperfections in

slowing growth and been overly optimistic about the short-run

benefits of rapid expansion in human capital. It thus suggests

that intergeneration complementarity and other forms of

adjustment costs, as well as to credit constraints, may prevent

rapid convergence between poor and rich countries.

30 Some have suggested that Kenya's education system is illsuited to the needs of the country, and indeed Kenya has instituted a series of educational reforms to re-orient the system towards technical and agricultural skills. But, unemployment is high among graduates of technical schools as well. For example, one informal study cited by Lockhart (1981) found that, a year after graduation, 588 of graduates of technical secondary schools were still looking for work. 


\section{References}

Barro, Robert J., N. Gregory Mankiw and Xavier Sala-i-Martin, "Capital Mobility in Neoclassical Models of Growth" unpublished paper. Harvard University, Cambridge, MA. (1992)

Barro, Robert $J$. and Xavier Sala-i-Martin, "Convergence," Journal of Political Economy, 100:2 (1992a)

Harvard University.

Benhabib, Jess and Aldo Rustichini, "Vintage Capital, Investment, and Growth," Journal of Economic Theory, 55:2, December $1991,323-339$.

Chari, V.V. and Hugo Hopenhayn, "Vintage Human Capital, Growth, and the Diffusion of New Technology," Journal of Political Economy, 99:6, 1142-1165. December 1991 .

Cohen, Daniel and Jeffrey Sachs, "Growth and External Debt under Risk of Debt Repudiation," European Economic Review, 78, December 1986, 1138-1154.

Dowrick, S, and D. Nguyen, "OECD Comparative Economic Growth 1950-85: Catch-Up and Convergence," American Economic Review, 79, December 1989, 1010-1030.

Freeman, Richard B., "Overinvestment in College Training?" Journal of Human Resources, X (Summer, 1975a), 287-311.

"Supply and Salary Adjustments to the Changing Science Manpower Market: Physics 1948-1973, "American Economic Review, 65 (1975b): 27-39.

- "A Cobweb Model of the Supply and Starting Salary of New Engineers," Industrial and Labor Relations Review, 29 (1976): 236-248

Goldin, Claudia, and Robert A. Margo, "The Great Compression: The Wage Structure in the United States at Mid-Century," Quarterly Journal of Economics, February, 1992.

Hopcraft, Peter N., Human Resources and Technical Skills in Agricultural Development: An Economic Evaluation of Educative Investments in Kenya's Small Farm Sector, PhD. dissertation, Stanford University, 1974.

Katz, Larry and Kevin M. Murphy, "Changes in Relative Wages, 1963-87: Supply and Demand Factors," Quarterly Journal of 
Economics, February, 1992.

Killick, Tony (Ed.), Papers on the Kenyan Economy, 1981, Heinemann Educational Books: London.

Kremer, Michael and James Thomson, "Complementarity and Substitutability of Human Capital of Different Generations," unpublished paper, 1992.

Lam, David, "Population Growth, Age Structure, and Age-Specific Productivity," Journal of Population Economics, 1989:2.

Lockhart, Lawrence, "The Economics of Nine Years Education For All," in Tony Killick (Ed.), Papers on the Kenyan Economy, 1981, Heinemann Educational Books: London.

Murphy, Kevin M. and Finis Welch, "The Structure of Wages," Quarterly Journal of Economics, February 1992. Vol. CVII No. 1 .

Pierce, Wayne Brooks, Occupational Choice: the Market for Lawyers, Unpublished Ph.D. dissertation, Department of Economics, University of Chicago, 1990.

Prescott, Edward C. and John H. Boyd, "Dynamic Coalitions: Engines of Growth," American Economic Review, May 1987, Vol. 77 , No. 2 .

Stokey, Nancy L. and Robert E. Lucas, Jr., with Edward C. Prescott, Recursive Methods in Economic Dynamics, 1989, Harvard University Press: Cambridge.

Taylor, Alan M., "External Dependence, Demographic Burdens and Argentine Economic Decline After the Belle Epoque," The Journal of Economic History, December 1993, Vol. 52, No 4.

Thias, Hans H. and Martin Carnoy, Cost Benefit Analysis in Education: A Case Study of Kenya. Washington, World Bank Staff Occasional Paper No. 14, 1972. Johns Hopkins Press.

Todaro, Michael P., "Education and National Economic Development," in Tony Killick (Ed.), Papers on the Kenyan Economy, 1981, Heinemann Educational Books: London.

World Bank, World Development Report, various issues. Oxford University Press: New York.

World Debt Tables, 1989-90. 


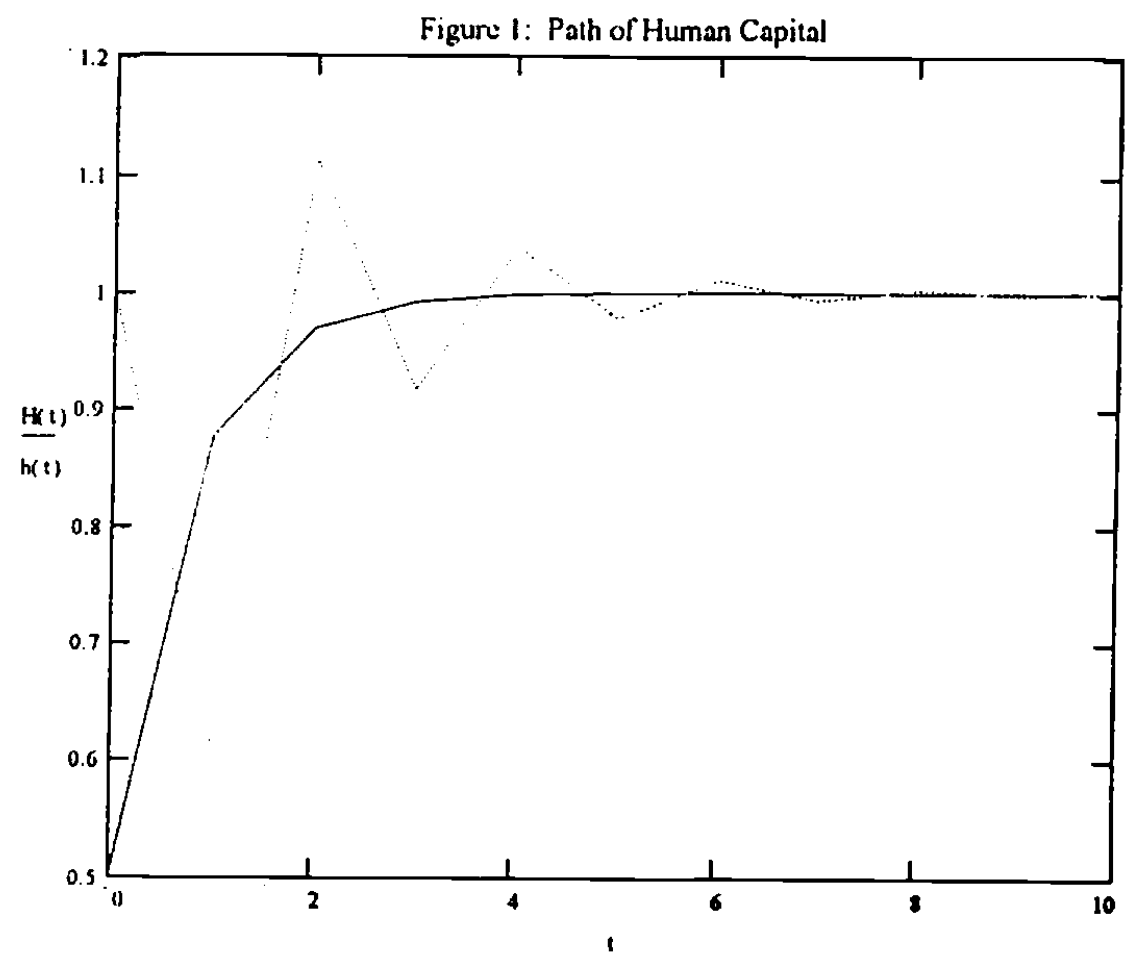

